\title{
PERANCANGAN SISTEM INFORMASI APLIKASI RENTAL MOTOR PADA JOGJA24 RENT GROUP MENGGUNAKAN JAVA DAN MYSQL
}

\author{
Muhamad Farhan ${ }^{1}$, Maria Cleopatra ${ }^{2}$, Diyan \\ Parwatiningtyas ${ }^{3}$ \\ Program Studi Teknik Informatika ${ }^{1}$, Program Studi Teknik Informatika ${ }^{2}$, \\ Program Studi Teknik Informatika ${ }^{3}$ \\ Fakultas Teknik dan Ilmu Komputer ${ }^{1}$, Fakultas Teknik dan Ilmu \\ Komputer $^{2}$, Fakultas Teknik dan Ilmu Komputer ${ }^{3}$ \\ Universitas Indraprasta PGRI ${ }^{1}$, Universitas Indraprasta PGRI ${ }^{2}$, Universitas \\ Indraprasta PGRI ${ }^{3}$ \\ farhan2604@gmail.com¹, mariacleopatra1313@gmail.com², \\ diane.tyas@gmail.com ${ }^{3}$
}

\begin{abstract}
Abstrak: Ilmu pengetahuan dan teknologi dapat membantu pekerjaan manusia dengan mudah. Hampir semua pekerjaan dapat dibantu oleh teknologi yang diciptakan oleh manusia sehingga dapat mengefisienkan waktu,tenaga,dan biaya. Salah satu yang terkena dampak perkembangan teknologi informasi adalah Jogja24 Rent Group. Pada kajian ini, perancangan sistem informasi aplikasi rental motor pada Jogja24 Rent Group menggunakan Java dan MySQL bertugas untuk mengolah data seperti penginputan data pelanggan, data petugas, data motor, data rental dan pengembalian, serta laporan-laporan yang dibutuhkan setiap bulannya. Tujuan penelitian ini adalah untuk mempermudah proses input data sehingga mempermudah petugas dalam melakukan proses pengolahan data, memperkecil terjadinya kesalahan dan informasi yang dihasilkan agar lebih akurat. Metode penelitian yang digunakan adalah metode observasi dan pendekatan grounded theory. Hasil dari penelitian ini berupa sistem informasi aplikasi rental motor yang dapat membantu Jogja24 Rent Group dalam menerapkan sistem yang lebih modern dan dapat mempermudah pengelolaan rental motor.
\end{abstract}

Kata kunci: Perancangan; Sistem Informasi; Rental Motor; Java; MySQL

\begin{abstract}
Science and technology can help human work with ease. Almost all jobs can be assisted by technology that is created by humans so that it can save time, effort and costs. One of those affected by the development of information technology is the Jogja24 Rent Group. In this study, the design of a motorbike rental application information system at Jogja24 Rent Group using Java and MySQL is tasked with processing data such as inputting customer data, staff data, motorbike data, rental and return data, as well as reports needed every month. The purpose of this research is to simplify the data input process so that it makes it easier for officers to process data, minimize errors and make the resulting information more accurate. The research method used is the method of observation and grounded theory approach. The result of this research is a motorbike rental application information system that can help Jogja24 Rent Group in implementing a more modern system and can simplify the management of motorbike rental.
\end{abstract}

Keywords: Design; Information Systems; Motorbike Rental; Java; MySQL

\section{PENDAhUluan}

Pada era modern sekarang ini perkembangan teknologi berkembang sangat pesat, terutama teknologi informasi komputer. Kebutuhan akan informasi sangat meningkat seiring perkembangan teknologi dan

Ciptaan disebarluaskan di bawah Lisensi Creative Commons Atribusi 4.0 Internasional. 
informasi [1]. Karena dengan adanya teknologi manusia dapat melakukan suatu pekerjaan dengan mudah. Hampir semua pekerjaan dapat dibantu oleh teknologi yang diciptakan oleh manusia sehingga manusia dapat mengefisienkan waktu,tenaga,dan biaya. Salah satu yang terkena dampak perkembangan teknologi informasi adalah Jogja24 Rent Group. Dalam perusahaan jasa rental hal yang akan lebih sering dijumpai adalah kegiatan pemesanan jasa tersebut. Banyak perusahaan hanya menuliskan daftar pemesanannya hanya menggunakan catatan tulis pada sebuah buku atau pada lembaran kertas form pemesanan saja. Sehingga tidak jarang ada kekeliruan akan pemesanan dikarenakan ada data yang hilang atau lupa tercatat. Hal ini menyebabkan sistem pemesanan pun menjadi kurang efektif, . Selama ini proses pemesanan dan pengolahan data pada Jogja24 Rent Group pun masih bersifat manual sehingga banyak kendala dalam pengolahan data pemesanannya. Pada Jogja24 Rent Group media penyimpanannya masih berupa arsip-arsip yang besar kemungkinan rusak atau hilang, sehingga menyulitkan dalam mengetahui perkembangan pada perusahaannya. Hal ini juga menyebabkan pengolahan data, pembuatan kwitansi serta pembuatan laporan dan perhitungan tidak bisa dilakukan dengan cepat.

Untuk itu diperlukan sebuah perancangan sistem agar semua kegiatan berjalan dengan baik, maka teknologi yang tepat adalah menggunakan komputerisasi, sehingga semua aktivitas yang bersifat manual diganti dengan menggunakan teknologi yang tepat sesuai kebutuhan. Komputerisasi sistem pemesanan sangat diperlukan sehingga akan memperkecil kesalahan serta dapat memberikan informasi dengan cepat, efektif dan efisien. karena selain menjamin keakuratan data computer juga dapat menghemat waktu, biaya serta dapat diakses dengan cepat dan mudah [2]. Pemakaian sistem informasi aplikasi rental motor pada Jogja24 Rent Group ini berfungsi untuk proses input data sehingga mempermudah karyawan dalam melakukan proses pengolahan data memperkecil terjadinya kesalahan dan informasi yang dihasilkan agar lebih akurat, dan dapat menampilkan laporan data pemesenan secara efektif dan berkala setiap bulannya sehingga dapat memberikan informasi lengkap.

\section{METODE DAN MATERI}

Metode penelitian yang digunakan adalah pendekatan grounded theory, studi kepustakaan, metode observasi dan metode wawancara data untuk mendukung penyempurnaan hasil dari penelitian ini.

\subsection{Grounded Theory}

Menurut Noor [3] "Pendekatan grounded theory adalah untuk menghasilkan atau menemukan suatu teori yang berhubungan dengan situasi tertentu. Inti dari pendekatan grounded theory ialah pengembangan suatu teori yang berhubungan erat kepada konteks peristiwa yang dipelajari”.

\subsection{Studi Kepustakaan (Library Research)}

Pengumpulan data dan informasi dari kutipan buku-buku, artikel-artikel, hasil laporan, serta bahan lainnya yang berkaitan dengan penelitian ini. Dari bahan-bahan tersebut diambil teori-teori yang dapat dijadikan landasan untuk menganalisa masalah yang ditemukan dalam penelitian dan digunakan untuk menyelesaikan masalah tersebut.

\subsection{Observasi}

Peneliti melakukan pengamatan langsung dengan sistem yang sedang berjalan, dengan pencatatan, dan pengumpulan data-data yang dilakukan pada Jogja24 Rent Group.

\subsection{Wawancara}

Teknik pengumpulan data dengan cara bertanya kepada Bapak Reza Haryanto Selaku Pemilik Jogja24 Rent Group yang bertanggung jawab dalam mengelola dan mengetahui kebutuhan dari pendataan. Jenis wawancara yang digunakan adalah wawancara tidak terstruktur yang diharapkan mendapatkan banyak informasi yang lebih mendalam atau hal baru sebagai penunjang pembahasan dan hasil penelitian.

\subsection{Perancangan Sistem}

Dalam menyempurnakan hasil dari penelitian ini, penulis mencoba menuliskan langkah-langkah yang digunakan untuk dalam Perancangan Sistem Informasi Aplikasi Rental Motor pada Jogja24 Rent Group

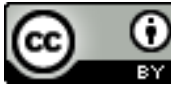

Ciptaan disebarluaskan di bawah Lisensi Creative Commons Atribusi 4.0 Internasional. 
menggunakan Java dan MySQL dengan metode Waterfall. Model waterfall adalah model klasik yang bersifat sistematis, berurutan dalam membangun software [4].



Gambar 1. Classic Life Cycle (Jogiyanto [5])

Menurut Mohamad Subhan [6] mendefinisikan bahwa "Perancangan adalah proses pengembangan spesifikasi baru berdasarkan rekomendasi hasil analisis sistem". Sedangkan sistem adalah suatu kesatuan utuh yang terdiri dari beberapa bagian yang saling berhubungan dan berinteraksi untuk mencapai tujuan tertentu.

\subsection{Sistem Informasi}

Menurut Subhan (2012:18) "Sistem informasi merupakan kumpulan dari perangkat keras dan perangkat lunak komputer serta perangkat manusia yang akan mengolah data menggunakan perangkat keras memegang peranan yang penting dalam sistem informasi. Data yang akan dimasukkan dalam sebuah sistem informasi dapat berupa formulir-formulir, prosedur-prosedur dan bentuk data lainnya”.

\subsection{Aplikasi}

Menurut Jogiyanto [5], “Aplikasi merupakan program yang berisikan perintah-perintah untuk melakukan pengolahan data. Jogiyanto menambahkan aplikasi secara umum adalah suatu proses dari cara manual yang ditransformasikan ke komputer dengan membuat sistem atau program agar data diolah lebih berdaya guna secara optimal".

\subsection{Rental (Sewa)}

Penyewaan adalah suatu perjanjian dengan mana pihak yang satu mengikatkan dirinya untuk memberikan kepada pihak yang lainnya kenikmatan dari suatu barang [7].

\subsection{Java}

Menurut Nofriadi [8] "Bahasa pemrograman Java merupakan salah satu dari sekian banyak bahasa pemograman yang dapat dijalankan di berbagai sistem operasi termasuk telepon genggam”.

\subsection{MySQL}

Database server adalah server yang berfungsi untuk menangani database. Menurut Kadir [9] "Database adalah suatu pengorganisasian data dengan tujuan memudahkan penyimpanan dan pengaksesan data".

\section{PEMBAHASA DAN HASIL}

3.1. Aturan Bisnis Sistem Berjalan
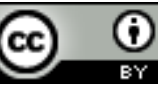

Ciptaan disebarluaskan di bawah Lisensi Creative Commons Atribusi 4.0 Internasional. 
Aturan bisnis sistem berjalan pada Jogja24 Rent Group adalah:

1. Setiap pelanggan wajib mengisi formulir pelanggan dan konfirmasi kepada petugas untuk melakukan rental motor yang tersedia.

2. Setelah mengisi formulir pelanggan, pelanggan bisa memilih jenis rental motor yang akan disewa dan segera melakukan pembayaran.

3. Pelanggan mendapatkan kwitansi pembayaran sebagai bukti pembayaran dari sewa motor yang telah dilakukan.

4. Bagian pengurus melaporkan data rental kepada pemilik Jogja24 Rent Group.

\subsection{Alternatif Penyelesaian Masalah}

Berdasarkan masalah-masalah yang dihadapi dalam melakukan rental motor pada Jogja24 Rent Group, maka penulis memberikan alternatif penyelesaian masalah, yaitu:

1. Untuk mengoptimalkan proses pengolahan data pelanggan, diperlukan sistem informasi aplikasi secara komputerisasi yang dapat digunakan dengan mudah dalam penggunaan dan pengolahan data pelanggan.

2. Dengan adanya sistem informasi aplikasi ini, pengolaan data pelanggan dan data petugas menjadi lebih mudah dengan adanya penyimpanan basis data menggunakan komputer.

3. Sistem informasi aplikasi yang sudah terkomputerisasi, memudahkan pelanggan dan petugas untuk melakukan kegiatan rental motor secara lebih cepat dan arsip data dapat tersimpan dengan baik menggunakan basis data secara komputerisasi.

\subsection{Aturan Bisnis Sistem Diusulkan}

Aturan bisnis sistem yang diusulkan dalam sistem informasi aplikasi rental motor pada Jogja24 Rent Group adalah sebagai berikut :

1. Data Pelanggan

Petugas memasukan data pelanggan dan menyimpan data tersebut ke dalam basis data pelanggan, yang kemudian petugas mengelola data untuk kepentingan adminstrasi pelanggan dalam rental motor.

2. Data Petugas

Petugas memasukan semua data petugas dan menyimpan data tersebut ke dalam basis data petugas, yang kemudian petugas mengelola data untuk kepentingan adminstrasi petugas dalam rental motor.

3. Data Motor

Petugas memasukan data motor yang akan digunakan untuk kegiatan rental motor dan menyimpan data tersebut ke dalam basis data motor, petugas mengelola data motor yang kemudian diteruskan ke bagian pengurus untuk kepentingan laporan data motor.

4. Rental Motor

Petugas memasukan data rental motor yang telah dilakukan oleh pelanggan dan menyimpan data tersebut ke dalam basis data rental, petugas mengelola data rental motor yang kemudian diteruskan ke bagian pengurus untuk kepentingan laporan data rental dan laporan data pengembalian.

5. Laporan

Bagian pengurus mencetak laporan data pelanggan, laporan data petugas, laporan data motor, laporan data rental dan laporan data pengembalian.

\subsection{Diagram Alir Data}

DFD menggambarkan penyimpanan data dan proses yang mentransformasikan data. Berikut ini adalah diagram alir data dalam pembuatan sistem informasi aplikasi rental motor pada Jogja24 Rent Group. 


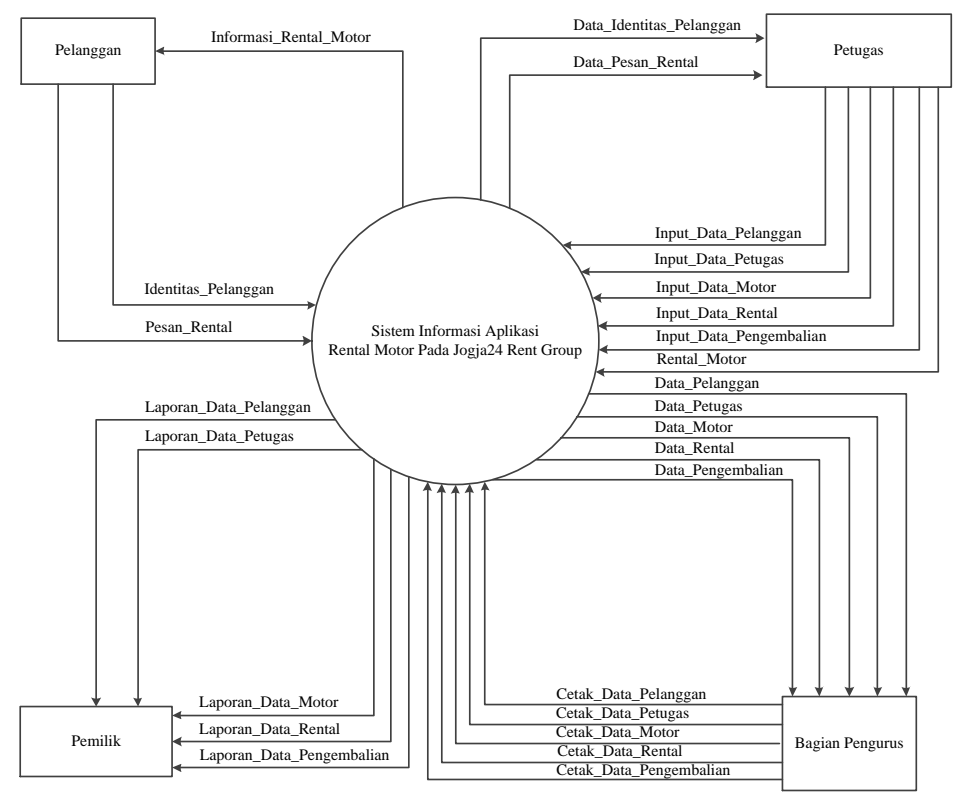

Gambar 2. Diagram Alir Data

\subsection{Entity Relationship Diagram}

ERD merupakan tools yang digunakan untuk memodelkan struktur data dengan menggambarkan entitas dan hubungan antara entitas (relationship) secara abstrak (konseptual) [10].

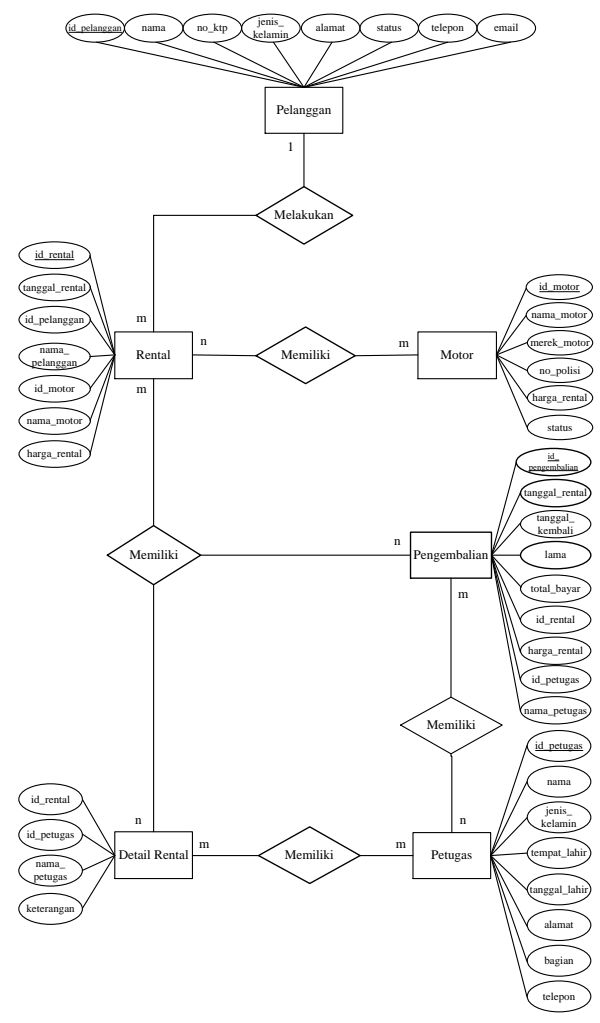

Gambar 3. Entity Relationship Diagram 
3.6. Tampilan Program

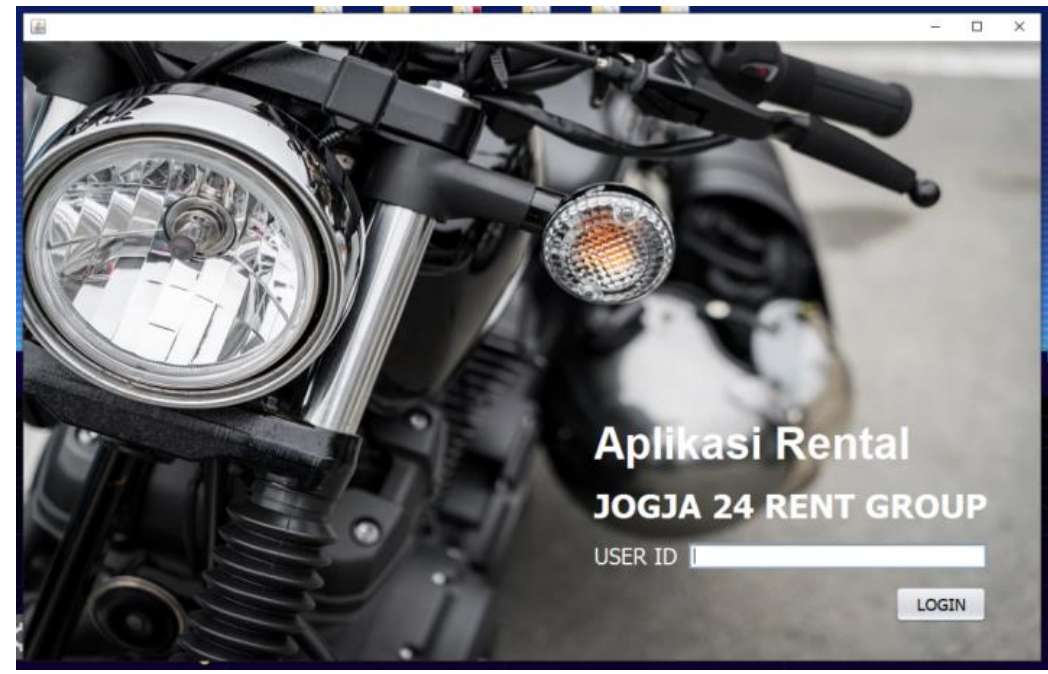

Gambar 4. Tampilan Layar Login

Login digunakan sebagai kata kunci sebelum memasuki menu utama. Pengguna harus memasukan user id dengan benar, maka menu utama akan tampil dan program siap untuk digunakan.

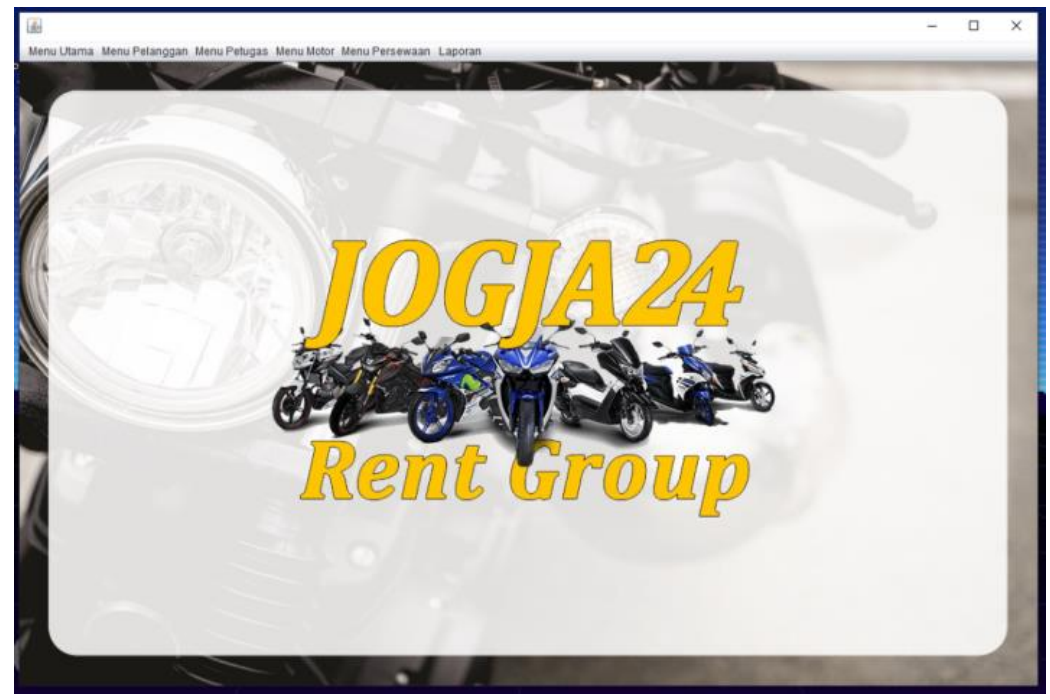

Gambar 5. Tampilan Layar Menu Utama

Tampilan menu utama berfungsi untuk menampilkan informasi ke menu-menu yang ada didalamnya, seperti menu pelanggan, menu petugas, menu motor, menu persewaan dan menu laporan. Menu pelanggan digunakan untuk memasukan dan melihat data pelanggan. Menu petugas digunakan untuk memasukan dan melihat data petugas. Menu motor digunakan untuk memasukan dan melihat data motor. Menu persewaan digunakan untuk memasukan dan melihat data rental dan data pengembalian. Menu laporan digunakan untuk mencetak laporan. 




Gambar 6.Tampilan Layar Form Pengembalian

Tampilan form ini berfungsi untuk informasi data pengembalian dengan mengisi tanggal rental, tanggal kembali, id rental, harga rental, lama, total bayar, id petugas, nama petugas. Tombol simpan digunakan untuk menyimpan data pengembalian yang sudah dimasukan. Tombol hapus digunakan untuk menghapus data pengembalian yang sudah tersimpan. Tombol ubah berfungsi untuk mengubah data pengembalian yang sudah tersimpan. Tombol batal digunakan untuk membuat lembar form kembali kosong. Tombol + digunakan untuk mengambil set data yang dibutuhkan. Tombol bukti bayar digunakan untuk mencetak keluaran bukti pembayaran.

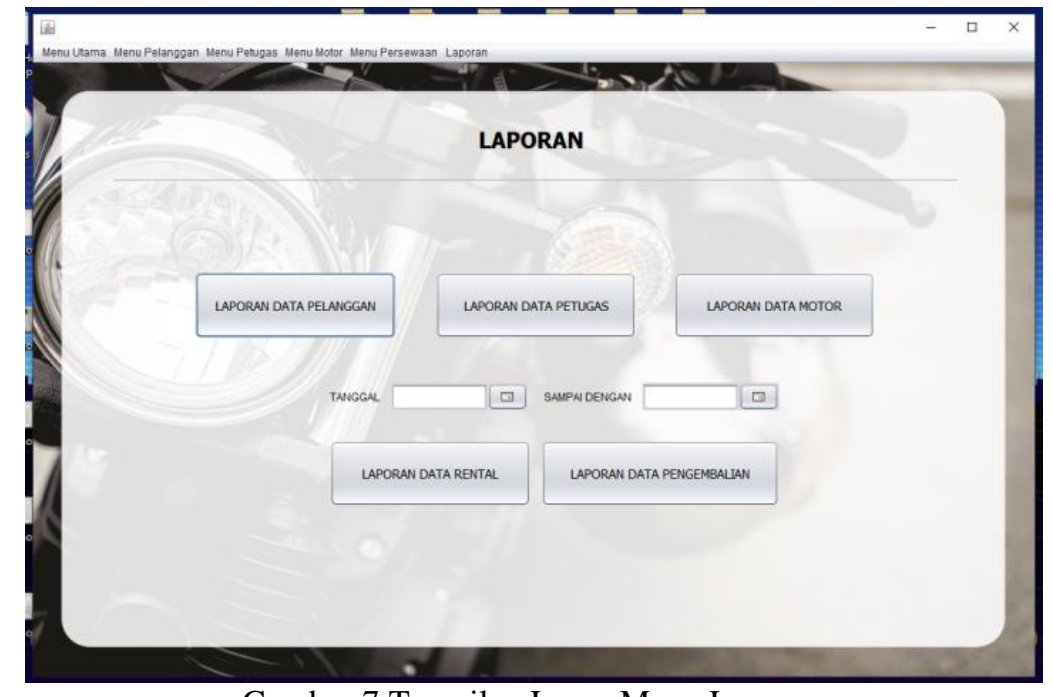

Gambar 7.Tampilan Layar Menu Laporan

Tampilan form ini berfungsi untuk mencetak laporan berupa laporan data pelanggan, laporan data petugas, laporan data motor, laporan data rental dan laporan data pengembalian. Laporan data rental dan laporan data pengembalian dapat di cetak dengan mengisikan periode tanggal 1 sampai dengan periode tanggal 2 kemudian pilih tombol laporan data rental atau laporan data pengembalian. 


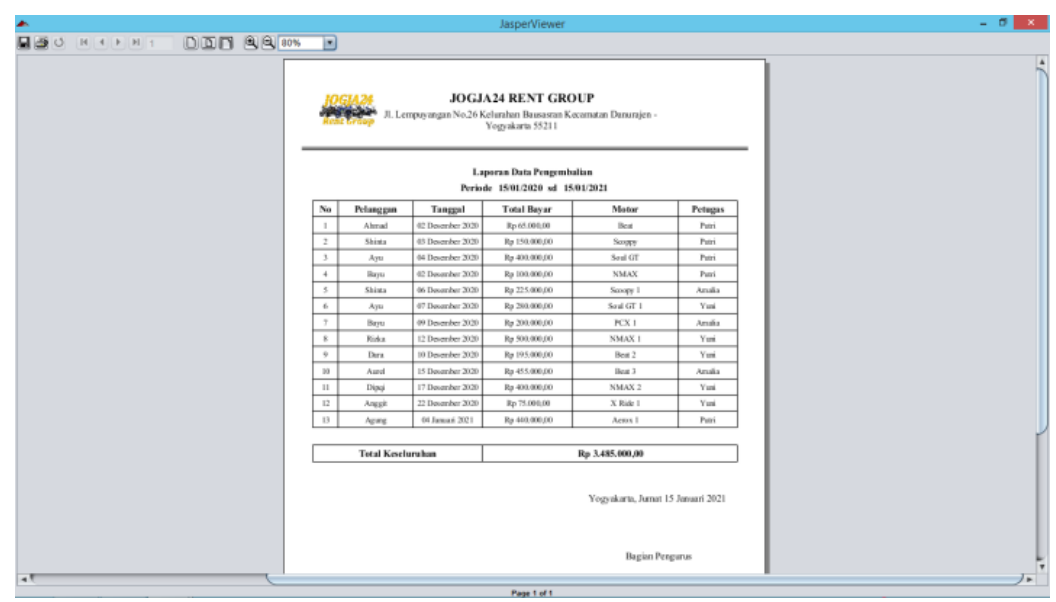

Gambar 8. Tampilan Laporan Data Pengembalian

\section{KESIMPULAN}

1. Dengan adanya perancangan sistem informasi aplikasi rental motor ini dapat memudahkan para petugas dan karyawan dalam melakukan pendataan Rental Motor pada Jogja24 Rent Group.

2. Dengan menggunakan perancangan sistem informasi aplikasi rental motor ini dapat mengefisiensikan waktu serta mempermudah kinerja para petugas dan karyawan dalam pembuatan laporan Rental Motor.

3. Dengan adanya perancangan sistem informasi aplikasi rental motor mempermudah para petugas dan karyawan Jogja24 Rent Group dalam pencarian data dan data-data yang disimpan lebih terstruktur dan juga lebih aman.

\section{REFERENASI}

[1] W. Nurhayati and H. Sugiarto, “Aplikasi Sistem Informasi Penyewaan Motor Berbasis Dekstop,” vol. 12, no. 2, pp. 21-25, 2020.

[2] Y. Yudhono and N. Ismawati, “Aplikasi Penyewaan Motor Pada Rental Cahaya Abadi Di Jatiasih,” J. Sist. Informasi, Teknol. Informasi, dan Komput., vol. 9, p. 2, 2019.

[3] J. Noor, Metodologi Penelitan:Skripsi,Tesis,Disertasi dan Karya Ilmiah. Jakarta: Kencana, 2017.

[4] A. Setiawan, R. Avrizal, and R. Nurul Auliya, "Implementation of Motorcycle Rental Information System at the Trans Jaya Tangerang," Systematics, vol. 2, no. 2, pp. 72-78, 2020.

[5] Jogiyanto, Analisis dan Desain Sistem, Edisi IV. Yogyakarta: Andi Offset, 2010.

[6] M. Subhan, Analisa Perancangan Sistem. Yogyakarta: CV. Andi Offset, 2012.

[7] E. Yogaswara and C. Prihartanto, "Perancangan Sistem Informasi Penyewaan Bus Pariwisata," Lentera Ict, vol. 1, no. 1, pp. 34-43, 2013.

[8] Nofriadi, Java Fundamental Dengan Netbeans 8.0.2. Yogyakarta: Deepublish, 2015.

[9] A. Kadir, Pengenalan Sistem Informasi. Yogyakarta: Andi, 2014.

[10] B. Di, K. Sabang, and B. Android, "Journal of Informatics and Computer Science Vol . 3 No . 1 April 2017 Universitas Ubudiyah Indonesia INFORMATION SYSTEM OF MOTOR VEHICLE SERVICE Journal of Informatics and Computer Science Vol . 3 No . 1 April 2017 Universitas Ubudiyah Indonesia," vol. 3, no. 1, pp. 1-14, 2017. 